\title{
Forms and functions of the contemporary school: erasures between modernity, postmodernity and neoliberalism
}

\author{
Formas e funções da escola contemporânea: rasuras entre \\ modernidade, pós-modernidade e neoliberalismo
}

\section{Formas y funciones de la escuela contemporánea: borrados entre modernidad, posmodernidad y neoliberalismo}

\author{
George Saliba Manske ${ }^{1}$ (D) Liliane Geisler $^{1}$ iD \\ ${ }^{1}$ Universidade do Vale do Itajai, Itajaí, Santa Catarina, Brasil. \\ Corresponding author: \\ George Saliba Manske \\ Email: gsmanske@yahoo.com.br \\ How to cite: Mancke, G. S., \& Geisler, L. (2021). Forms and functions of the contemporary school: erasures between \\ modernity, postmodernity and neoliberalism. Revista Tempos e Espaços em Educação, 14(33), e16347. \\ http://dx.doi.org/10.20952/revtee.v14i33.16347
}

\begin{abstract}
This essay aims to problematize how certain school practices are enabled and supported for their existence, since different economic discourses in statements that materialize in the school and students. From this perspective, we believe that rethinking the school space with characteristics of modernity in a post-modern scenario is to enhance essential functions for the continuation of our own existence as a public and collective institution. We assume that to question the potentialized discourses of neoliberalism in education, rooted in the development of economic progress and the ultra-market, in which interests and responsibilities of the State shift and mix from private social actions in the school space with interests of market, becomes an indispensable task. We argue that neoliberal marketing languages are active in the forms and functions of contemporary schools, advocating the need for a debate that emphasizes education based on the development of school subjects committed to the public and the social.
\end{abstract}

Keywords: School. Curriculum. Modernity. Neoliberalism. Cultural Studies.

\section{RESUMO}

Este ensaio tem como objetivo problematizar como determinadas práticas escolares são validadas e amparadas para sua existência supondo diferentes discursos econômicos em enunciados que se materializam no cenário da escola e dos escolares. Nessa perspectiva, acreditamos que repensar o espaço escolar com características da modernidade em um cenário pós-moderno é potencializar funções imprescindíveis para continuação da nossa própria existência como instituição pública e 
coletiva. Partimos do pressuposto de que questionar os discursos potencializados do neoliberalismo na educação, enraizados para o desenvolvimento do progresso econômico e do ultra mercado, no qual interesses e reponsabilidades do Estado se deslocam e se mesclam a partir de ações sociais privadas no espaço escolar com interesses de mercado, passa a ser uma tarefa indispensável. Arguimos as linguagens mercadológicas neoliberais como atuantes nas formas e funções da escola contemporânea, advogando a necessidade de um debate que prime pela educação com base em desenvolvimentos de sujeitos escolares comprometidos com o público e o social.

Palavras-chave: Escola. Currículo. Modernidade. Neoliberalismo. Estudos Culturais.

\section{RESUMEN}

Este ensayo tiene como objetivo problematizar cómo ciertas prácticas escolares están validadas y respaldadas para su existencia asumiendo diferentes discursos económicos en declaraciones que se materializan en el escenario escolar y de los escolares. Desde esta perspectiva, creemos que repensar el espacio escolar con características de modernidad en un escenario posmoderno es potenciar funciones esenciales para la continuidad de nuestra propia existencia como institución pública y colectiva. Asumimos que cuestionar los discursos potencializados del neoliberalismo en educación, arraigado para el desarrollo del progreso económico y del ultra mercado,en el que los intereses y responsabilidades del Estado se trasladan y se mezclan desde la acción social privada en el espacio escolar con los intereses del mercado, se convierte en una tarea indispensable. Sostenemos que los lenguajes de marketing neoliberal están activos en las formas y funciones de la escuela contemporánea, abogando por la necesidad de un debate que busque una educación basada en el desarrollo de asignaturas escolares comprometidas con lo público y lo social.

Palabras clave: Escuela. Currículo. Modernidad. Neoliberalismo. Estudios culturales.

\section{PROBLEMATIZAÇÕES E RASURAS SOBRE A ESCOLA E CURRÍCULO ESCOLAR NA ATUALIDADE}

Discutir temas relativos a organização curricular nos espaços escolares formais é, sobretudo no cenário brasileiro atual e provavelmente em anos que se sucederão, uma tarefa política. Os diversos ataques que a escola tem recebido, especialmente a pública, naquilo que desenvolve em ações e perspectivas progressistas tem sido a tônica e a retórica de narrativas inseridas em discursos heterogêneos que, em certa medida, possuem em comum tradições conservadoras de mundo e buscam homogeneizar as práticas político-pedagógicas que na escola se inserem e são postas em funcionamento. Entrementes, é preciso registrar que a escola (e consequentemente sua organização curricular) sempre foi alvo de disputas em torno de suas funções, formas, saberes e modos de ação (Moreira \& Silva Júnior, 2016). No entanto, hodiernamente, frente a um proclamado chamado de defesa da escola tradicional em prol dos intitulados 'bons costumes', é necessário repensar discussões que há pouco pareciam já bastante debatidas, quais sejam, a suspensão das metanarrativas da modernidade e seu caráter disciplinar e regulador de subjetividades e coletividades.

O espaço escolar e a condição de ser escola na contemporaneidade perpassa por questionamentos, confrontos e, em alguns casos, por convergências de projetos de mundo díspares, tais como aqueles promulgados pela modernidade, calcados na regulação disciplinar de espaços físico-espaciais, e outros cravados na contemporaneidade em modelos de mercados neoliberais balizados pela ampla abertura de ações e virtualização dos espaços-corpos. Tais problemáticas podem ser consideradas como urgentes de serem debatidas, em especial, aquelas que tangenciam o contexto contemporâneo da virtualização do ensino, as implicações disto para outras formas de ser aluno e professor, e as relações com o trabalho docente (Nunes et al., 2021).

Entrementes, esses tópicos de discussão tal como o recém aludido se emaranham em problematizações mais amplas acerca das possibilidades de emergência de formas e funções escolares, nas quais projetos de sociedade plurais atravessam e constituem a instituição escolar. 
Nessa perspectiva, alguns questionamentos gerais tornam-se possíveis para supor algumas razões pelas quais as condições atuais da escola precisam ser suspendidas e suspeitadas: Qual é o papel da escola? Será que na sua 'forma' a escola é mais potente que em sua 'função'? E mais: em relação a ações de reorganização da escola em sua forma (vide propostas de 'ensino doméstico') ou função (vide o retorno de propostas nacionalistas, moral e cívica, a retirada de filosofia e sociologia do currículo, interdição de temas sobre pluralidade, entre outros) mediante discursividades que movimentam enunciados neoconservadores, não seria justamente o momento de retomar (regressar!?) a princípios humanistas, modernos, mesmo diante de cenários culturais que conclamam uma condição de modernidade tardia, líquida ou pós-modernidade?

Em suma, essas hipóteses se baseiam em enunciados que ora se situam nos discursos da modernidade e ora se situam nos discursos da assim chamada pós-modernidade ${ }^{1}$, na qual os embates em torno da escola e as possibilidades de ser aluno parecem cada vez mais em disputa. Assumimos que esses discursos possibilitam a condição de existência da escola e escolares do modo como são, na constituição de verdades em um determinado tempo e espaço, enquanto produto e produtores. Como já anunciou Foucault, "todo sistema de educação é uma maneira política de manter ou de modificar a apropriação dos discursos, com os saberes e os poderes que eles trazem consigo" (Foucault, 2014, p. 41). Nessa contextualização, este ensaio tem como objetivo problematizar como determinadas práticas escolares são validadas e amparadas para sua existência supondo os diferentes discursos possíveis em enunciados que permitem o cenário da escola e dos escolares serem do modo como são, argumentando possíveis relações de saber e poder em sua constituição. Com este objetivo, centralizar a cultura nas discussões, colocando ênfase no seu significado político, pode ser uma tarefa produtiva no campo dos Estudos Culturais em educação. É necessária uma agenda de discussão que problematize o cenário atual dos debates em torno da função da escola e discuta sobre uma linha tênue as diferentes funções que a escola pode ter em projetos de mundo distintos e sob disputa.

\section{PENSAR A ESCOLA PELO CURRÍCULO: ESTUDOS CULTURAIS E PÓS-ESTRUTURALISMO}

É comum nas apresentações e introduções de livros, coletâneas e artigos que versam sobre currículo encontrarmos assertivas na direção de justificar o interesse pelo assunto, e isso das mais variadas formas. Esse interesse decorre da preocupação de setores da sociedade em compreender os processos de formação de sujeitos que serão os futuros cidadãos de nossas sociedades, merecendo destaque o fato de que esses interesses ocorrem com distintas ênfases de acordo com os propósitos de cada indivíduo ou grupo social. Outros ainda afirmam que "o currículo constitui hoje alvo privilegiado da atenção de autoridades, políticos, professores e especialistas", privilégio esse atestado "pelas constantes reformulações dos currículos dos diversos graus de ensino, bem como pela produção teórica do campo" (Moreira, 2012, p. 7). É na esteira desses argumentos que problematizações acerca da construção de currículos e, em especial, a disputa por tais construções torna-se central para o debate escolar atual.

Tal como refere Silva (2007), o termo currículo deriva da raiz curriculum, que pode ser compreendida como pistas de corrida, e, em sua forma e função, seleciona trechos a serem percorridos, precisa de indivíduos para percorrer, leva a algum lugar e, por fim, destaca e elege uma moral e valores. No entanto, é preciso estar atento para o fato de que uma pista não é algo transcendente, que esteja já e desde sempre pronta e a espera de alguém que a percorra. Uma pista é construída. Uma pista não tanto seleciona trechos como é o resultado de uma seleção de trechos.

\footnotetext{
${ }^{1}$ Aqui nos valemos do termo pós-modernidade para nos referirmos, de forma genérica, a um conjunto de propostas que apontam, sobretudo, para rupturas epistemológicas em relação aos princípios e pilares da modernidade, sejam essas perspectivas denominadas de modernidade líquida, modernidade tardia, entre outros. Embora sabidos das diferenças que possuem entre sim, agrupamos tais perspectivas muito mais em torno e suas semelhanças, a saber, a compreensão de abandono ou questionamentos das promessas e grandes narrativas da modernidade.
} 
Uma pista não tanto busca um fim quanto há um fim estipulado e elaborado que produz uma pista para que nele se chegue. Enfim, se pensarmos num currículo como pista, temos que compreender que um currículo não apenas seleciona, mas é o resultado de uma seleção. Um currículo não tanto tem um fim quanto há uma finalidade que constrói um currículo. E é sobre essa perspectiva de currículo como construção em que se pode fazer análises sobre a função e forma da escola contemporânea.

Silva (2007, p. 15) também assinala que um "currículo é sempre o resultado de uma seleção: de um universo mais amplo de conhecimentos e saberes seleciona-se aquela parte que vai constituir, precisamente, o currículo". E mais adiante, o autor salienta que um currículo busca modificar as pessoas, almeja produzir um determinado tipo de sujeito. Um currículo, então, é resultado de uma seleção de conhecimentos e de um sujeito que busca formar. E é sobre esses aspectos fundantes do currículo que é necessário que estejamos atentos no contexto atual, tendo em vista que há em curso novos direcionamentos de produção de currículos nacionais, desde as diferentes direções tomadas nas inúmeras versões da Base Nacional Comum Curricular (BNCC) mediante influência de transições de governos na esfera federal, até as atuais propostas de privatização de universidades públicas, incentivos a modalidade de ensino à distância, ensino domiciliar, retirada de disciplinas das áreas das humanidades, aumento de recursos a cursos tecnólogos, entre outros. Todas essas ações produzem currículo; selecionam saberes; intentam um tipo específico de sujeito e subjetividades, almejam uma finalidade de formação; sustentam-se por uma moral específica, nesse caso, neoconservadora e ultraliberal.

Assumiremos nesse ensaio uma noção de currículo desde uma perspectiva cultural, centrada no campo dos Estudos Culturais e com aporte de referencial pós-estruturalista. Pensar o currículo a partir do campo dos Estudos Culturais possibilita não pensar mais em currículo, no singular, mas em currículos, no plural, visto que este termo é ampliado e compreendido como múltiplas organizações sistematizadas de produções históricas, linguísticas e sociais de saberes que são postos em circulação em múltiplos espaços sociais, os quais, ao estarem atrelados as culturas específicas de cada grupo, ensinam modos de ser e estar no mundo. Assim, um currículo é entendido como um processo de construção social disputado em meio às relações de poder, como o resultado de diferentes lutas em torno da definição de significados e de representações que permeiam tal artefato cultural.

Ao conceber o currículo desde uma perspectiva cultural apoiada num referencial pósestruturalista, a ênfase no currículo passa a residir, também, no papel central e constitutivo da linguagem. Entretanto, seria necessário destacar que não podemos simplesmente propor "uma teoria pós-estruturalista do currículo, mesmo porque o pós-estruturalismo, tal como o pósmodernismo, rejeita qualquer tipo de sistematização" (Silva, 2007, p. 122). Mas há, continua o autor, "certamente uma atitude pós-estruturalista" em muitos estudos sobre o currículo.

Uma atitude pós-estruturalista do currículo enfatizaria, em primeiro lugar, o caráter de construção do conhecimento e dos significados presentes no currículo, construção essa realizada através da linguagem e atravessada por relações de poder. Em segundo lugar, a ênfase pósestruturalista de currículo não se centraria nas análises dos significados e dos saberes do currículo, embora sejam necessárias análises desses, mas se centraria nas análises dos processos de construção e de seleção dos saberes e significados que constituem o currículo, ou seja, desloca a ênfase dos significados para os processos de significação, da verdade para os processos de veridicação, assim como seus efeitos nas produções de sujeitos. Portanto, uma atitude pósestruturalista do currículo enfatizaria o caráter de construção do currículo e(m) seus processos e efeitos, disputas e relações de força, legitimidades e silenciamentos.

Numa atitude pós-estruturalista em relação ao currículo, este também é compreendido como um modo de linguagem. Através do currículo e de seus efeitos é que sujeitos dão sentido ao mundo, às coisas, aos acontecimentos e a si mesmos de determinados modos e não de outros. Um 
currículo como linguagem implica afirmar seu caráter constitutivo do mundo e sua natureza "arbitrária e ficcional por ser histórico e socialmente construído" (Corazza, 2001, p. 10). Um currículo, desde esse entendimento, corporifica e é corporificado nas práticas sociais, é produto e produtor de verdades que sustentam sua própria existência.

Além de problematizarmos o caráter construído do currículo, enfatizando os processos de sua construção, e entendê-lo como linguagem, ou seja, que o currículo funciona como modos de constituir verdades e realidades, autores como Silva (2007) e Corazza (2007) discutem outros elementos a serem incorporados para a compreensão e problematização do currículo, entre eles, o conceito de poder. Ambos autores acenam para a importância das relações de poder presentes nos processos de construção do currículo. Segundo Silva,

da perspectiva pós-estruturalista, podemos dizer que o currículo é também uma questão de poder [. . . ] Selecionar é uma operação de poder. Privilegiar um tipo de conhecimento é uma operação de poder. Destacar, entre as múltiplas possibilidades, uma identidade ou subjetividade como sendo a ideal é uma operação de poder (SILVA, 2007, p. 16).

O poder atravessa, então, a construção curricular assim como seus efeitos. E é na esteira dessas perspectivas teórico-metodológicas que propomos discutir em seguida quais formas e funções que os estudos de currículo podem colocar em suas agendas de debates, tendo vista os ataques que as escolas tem sofrido mediante uma onda de manutenção de moral tradicional, em seus efeitos de saber, poder e subjetividades. Nos parece que o tão 'suspeito' projeto moderno de escola crítica e progressista em suas ênfases humanistas, já muito debatido em teorizações pós críticas do currículo, precisa ser revisitado a fim de, ao menos, retomar algumas de suas bases para frear os impulsos conservadores que temos vivenciado.

\section{RASURAS DO EU, EM ‘NÓS’}

Temos como pressuposto que a identidade é movida pela incerteza, pela crise, tendo relevância cultural, social e sobretudo política na pós-modernidade. Para Hall (2019) é possível perceber a identidade como diáspora, ou seja, não fixa, com deslocamento, dispersão. É neste cenário da pós-modernidade que o ser aluno e o ser escola se constituem. Hall (2019) apresenta três tipos de sujeito para compreender o perfil da atual identidade cultural plurificada e inconstante: o primeiro seria o sujeito do lluminismo, com características de pessoa humana centrada, unificada, dotado de capacidades da razão. O segundo seria o sujeito sociológico, que estava traduzido a crescente complexidade do mundo moderno, no qual a identidade era construída na interação entre indivíduo e sociedade. E o terceiro, que está caracterizado pela ideia de que a identidade estável está fragmentada e composta por várias identidades, entendendo que este não tem uma identidade fixa, essencial e permanente, ou seja, seria perceber a subjetividade visualizada enquanto forma histórica específica, portanto, contextualizada.

A ideia de que do aluno se constrói além e no interior dos muros da escola permite perceber quais dispositivos sustentam os discursos sobre a formação dos "eus" escolares. Costa et. al (2003, p. 68) dizem que "tudo que acontece na escola tem fios e tramas dentro e fora da escola, e que não é possível negligenciar isso", ou ainda, dito de outro modo, como um "tênue deslocamento que se propõe praticar na história das ideias e que consiste em tratar, não das representações que pode haver por trás dos discursos, mas dos discursos como séries regulares e distintas de acontecimentos" (Foucault, 2014, p. 56). Talvez pensar em uma genealogia do sujeito possibilite perceber como se deram alguns dos deslocamentos históricos e culturais que permeiam a escola e comunidade escolar, indicando como foram possibilitadas de serem como são hoje. Rose (2001) permite uma abordagem sobre a história do eu que esteja preocupada com o ser humano tal como ele é pensado, e assim, seu domínio de investigação é o das práticas e técnicas sócio históricas e 
culturais, a qual dará o nome de genealogia da subjetivação. Para Foucault (2020, p. 15) a genealogia da subjetivação "é uma questão de analisar as problematizações através das quais o ser se dá podendo e devendo ser pensado, e as práticas a partir das quais essas problematizações se formam".

Cabe perguntar a partir dessa possibilidade de regime contemporâneo do eu, o porquê privilegiar um determinado tipo de "eu"/identidade ou subjetividade e não outro? Assim, por que os currículos compõem determinados tipos de conhecimentos e não outros? E mais, "não nos esquecemos de que o conhecimento que constitui o currículo está inextricavelmente, centralmente, vitalmente, envolvido naquilo que somos, naquilo que nos tornamos: na nossa identidade, na nossa subjetividade" (Silva, 2007, p. 15). Para Foucault (2014, p. 57), ao abordarmos tais questões é preciso atentar que existe um processo histórico que movimenta 3 princípios, quais sejam, o modo como se formaram por meio de "sistemas de coerção, séries de discursos; qual foi a norma específica de cada uma e quais foram suas condições de aparição, de crescimento, de variação". Assim também para constituição dos currículos, a partir de relações de poder, são selecionados saberes que são considerados importantes, essenciais, privilegiando saberes que direcionam, formam um tipo de sujeito ideal. Vale lembrar que "como uma luta em torno de valores, significados e propósitos sociais, o campo social e cultural não é apenas de imposição e domínio, mas também de resistência e oposição" (Silva, 2007, p. 49) para a produção dos currículos.

Nesse ínterim, a escola tem produzido modelos de subjetividades apropriadas: "nossa relação com nós mesmos tem a forma que tem por que tem sido o objeto de toda uma variedade de esquemas mais ou menos racionalizados, os quais têm moldado nossa existência como seres humanos em nome de certos objetivos" (Rose, 2001, p. 35-36), que estão relacionados ao modelo ser escola e ser aluno, tendo como exemplo a boa conduta, disciplina, eficiência etc. $E$ assim o discurso produz a existência de algo que pode ser dito, denominado o que é, como mecanismo de verdade. Temos na pós-modernidade códigos de saber que sustentam ideais escolares como "programas de governo que se veem como liberais e que têm sido definidos pelo problema de como indivíduos livres podem ser governados de maneira tal que eles vivam sua liberdade de forma apropriada" (Rose, 2001, p. 40-41). As questões escolares contemporâneas, que perpassam pelas discussões aqui alentadas sobre suas formas e funções, recaem nesses projetos de sujeito e mundo aqui assumidos como neoliberais, em que as organizações e ações que permeiam o espaço escolar, desde sua concepção passando pela proposição de leis e mecanismos reguladores atuam, ao nosso ver, na concretização dos ideais de (ultra) livre mercado.

\section{RASURAS DE ESCOLA E ESCOLARES}

A forma e função da escola atual baseada em pressupostos da modernidade podem ser colocadas sob suspeição (Larrosa, 2017). Para toda essa produção de saberes em disputa, se exercem relações de poder para selecionar um modo de ser escola e escolar. Tal como refere Silva (2007, p. 16) "privilegiar um tipo de conhecimento é uma operação de poder. Destacar, entre as múltiplas possibilidades, uma identidade ou subjetividade como sendo ideal é uma operação de poder". Apresentando algumas das possibilidades de resposta dos objetivos da educação escolarizada de hoje e entendendo a escola como um lugar na e da cultura, onde a cultura circula, é possível afirmar que a escola é um espaço de disputa e negociações, pois são tomados enquanto parte de práticas culturais. Estes espaços também incidem em locus de disputas e práticas de significações, permeadas por relações de saber e poder, que dentre suas práticas culturais e educativas atuam ensinando "sobre novas funções e significados de escola e de mundo na ordem contemporânea orientada para e pelo mercado" (Costa \& Momo, 2009, p. 524).

Apresentamos alguns registros culturais para exemplificar o modo como esses saberes que promovem a ideia de mercado e economia se entrelaçam e formam discursos no campo escolar, tal como vimos argumentando. Em primeiro lugar "consideramos que aquilo que começamos a 
observar na escola, nas formas como ela vai sendo articulada nas práticas sociais, políticas e econômicas da atualidade, é, então, intrínseco e imanente a esse jeito de a cultura operar no mundo de hoje" (Costa \& Momo, 2009, p. 525). Yúdice (2004) em sua obra "A conveniência da cultura" traz a ideia de força performativa, que segundo o autor é "entendida como os condicionamentos, as imposições e pressões exercidas pelo campo multidimensionado do social e pelas relações institucionais" (Yúdice, 2004, p. 64). Exemplos disso são os projetos sociais da pós-modernidade organizados pelas empresas privadas cada vez mais presentes no campo escolar: esses projetos se instauram com programações de segunda a sábado, atingindo o público infantil até idoso, na qual são vistos como "benfeitores sociais, que acumulam capital simbólico e valorizam seus produtos e empreendimentos, revelando-se engajados na promoção do bem-estar das populações" (Costa \& Momo, 2009, p. 529). Para Yúdice (2004) esse processo é entendido como extensão do biopoder, em termos foucaultianos, dirigidos para o governo da vida de populações, através de eixos centrados nos corpos individuais dos sujeitos, e também, centrado na regulação dos fenômenos próprios da vida, mas deslocados na atualidade em momentos de globalização.

Perante a possibilidade de formações instáveis e descentradas no qual o simbólico é fonte de identidade, o discurso e a linguagem tem papel fundamental (Costa \& Momo, 2009), considerando que a "construção da hegemonia passa agora pelas redes e indústrias de cultura e de comunicação, o que nos leva à urgência de considerar a centralidade do cultural destilado no cotidiano" (Mattelart \& Neveu, 2004, p. 13), é possível evidenciar que a cultura não é só utilizada para

resolver determinadas disfunções sociais, mas principalmente para administrar populações. É nesse sentido que projetos escolares buscam a performatividade para praticar o social, o que significa, que cada escola é instigada a compor suas redes de relações...visando a ações sociais orientadas para a solidariedade e para a promoção da cidadania responsável (Costa \& Momo, 2009, p. 527).

Assim, infinitos projetos, seja de ONG'S, empresas, universidades e até Estado sugerem e ensinam como a escola deve ser e como escolares devem se compor nesses discursos e saberes. 0 que antes era responsabilidade só do Estado agora é atribuição de inúmeros campos institucionais que produzem culturas escolares, ou melhor, escolarizadas, no cultural, enquanto campo não autônomo, como local de disputas sociais de sujeitos com identidades plurificadas, que inclusive estão vinculadas à construção sobre noção de gênero, sexualidade, etnia, nacionalidade, etc, configurando o sujeito aluno atual.

Entender a escola, o contexto pedagógico e seus atores sociais contemporâneos é repensála "sem cair na nostalgia da velha escola" (Dussel, 2017, p. 107), mas é também não abandonar as características da modernidade que a sustentam. É pensar nas condições materiais e estratégicas, nas políticas e na cotidianidade do escolar. Tratar dessas instabilidades do mundo contemporâneo é constituir rupturas com a ordem estabelecida, em seus diversos campos culturais, dentre eles a Educação. Pensar em manter características da escola moderna não seria ignorar o atual modelo contemporâneo de sociedade? Segundo Larrosa (2017), temos a possibilidade de manter uma ideia de educação em um contexto novo, no qual se mantenha a escola pública sem a destruição do público. Faz-se uma crítica sobre a própria crítica escolar contemporânea promovida por características da pós-modernidade. Quando na atualidade se faz a crítica sobre a falta de motivação dos jovens na escola, justificados pelos modelos de ensino-aprendizagem estarem defasados em relação ao mundo pós-alfabético que se vive, que discursos apoiam essa problemática? Quando na atual conjuntura educacional tem-se uma crítica sustentada sobre a distorção na relação entre o sistema educacional e o mundo do trabalho, onde formação profissional e escola pública se encontram? Quais são os fios condutores que sustentam essa ideia de sociedade e realidade escolar? 
Para Larrosa (2017), essas críticas estão sustentadas na falta de vontade sobre o público, na qual o interesse educacional da modernidade, de todos sobre todos, está sendo progressivamente destruído pela vontade mercadológica na educação. O que está em pauta para Larrosa (2017) é a defesa dos conceitos de educação do Século XIX, que Arendt (2016) define em dupla responsabilidade: educação como lugar onde decidimos se amamos o mundo o bastante a ponto de assumir uma responsabilidade por ele e assim transmiti-lo a nossos descendentes; e se amamos as nossas crianças o bastante a ponto de não abandoná-las e prepará-las para renovar um mundo comum, preservando a infância. Pensamos que para esses conceitos de educação seja preciso "imaginar dispositivos, tecnologias, artefatos ou saberes que dialoguem com as condições atuais do saber e que se inscrevam nas formas concretas com que hoje se faz escola" (Dussel, 2017, p. 107). Como fazer isso se a escola na ordem contemporânea está orientada para e pelo mercado?

Arendt (2016) discute a evidência da crise na educação a partir de três atividades humanas fundamentais. Dentre as três atividades humanas fundamentais se tem o labor e o trabalho, pertencentes a esfera do privado, e a ação, que está relacionada a esfera do público e que se tornou desinteressante aos ideais do mercado. Portanto, com a teoria do conhecimento de Descartes, orientada pela razão sobre os sentidos, converteu-se a necessidade subjetiva, sendo esta produzida no campo do espaço público, ou melhor, nos discursos produzidos na cultura, em necessidade objetiva, cultivando o tecnicismo para o trabalho e mercado, definido pela autora, como declínio do saber do senso comum. Conclui-se, assim, que o "racionalismo cartesiano que ensinou o ocidente a desconfiar dos sentidos e do senso comum, acabou por destruir não apenas o sentido de "mundo" ou de "realidade" - o que permite pensar em termos de espaço público - como também destruiu a concepção de verdade inerente a este espaço" (Callegaro, 2012, p. 263).

É na esteira das crises da educação contemporânea, sobretudo a partir dos investimentos de cunho neoliberal que atuam na escola pela lógica de mercado, que urge um necessário debate sobre suas formas e funções, atentando, especialmente, para as diferentes discursividades que atravessam a escola e seus docentes. Práticas marcadas pelas linguagens de mercado, tais como os projetos de capacitação docente que se valem de argumentos e termos mercadológicos que valorizam metas alcançadas, inclusive as colocando sob a égide de premiações, tais como um banco, precisam ser questionados. Não obstante, estudos tem indicado como tais pressupostos atravessam o cenário e debate escolar atual (Mendes, Cardoso \& Matos, 2019), reforçando as disputas entre educação e linguagem de mercado, reiterando a necessária postura crítico reflexiva em torno do tema.

\section{RASURAS DE POLÍTICAS PÚBLICAS EDUCACIONAIS}

Não só no ocidente, como em nível mundial, percebe-se um fenômeno internacional quanto os aspectos da privatização da educação e da política educacional, movendo políticas públicas educacionais e transformando serviços da educação em mercadorias, que precisamente influenciam, produzem e constroem os currículos, como também determinam formas e funções escolares. Não é nosso interesse simplificar as políticas públicas acreditando que elas são criadas só para beneficiar a minoria elitista e burguesa do poder e nem acreditar que não são interesses múltiplos sobre o como existir ou não uma política pública (Souza, 2006).

Ball (2006) apresenta dois tipos de política, que traduzidos para o âmbito educacional, produzem determinados efeitos. São esses: a política como texto e a política como discurso. A política como texto é a política que pode e já foi dita, como exemplo dos documentos já produzidos para direcionar as práticas escolares (Diretrizes, BNCC, Projeto Político Pedagógico), que se materializaram a partir de discursos que deram possibilidade da sua existência, tanto como forma, quanto seu objetivo e funcionalidade. A política do discurso problematiza sobre o que está estabelecido, apresentando enunciados que permitem identificar alternativas para seleção das 
opções, dentro de um contexto de influência, ou seja, que discursos sustentam uma determinada disciplina escolar existir ou não, ser excluída ou incluída, como por exemplo, o que permite a Educação Física, num documento como a BNCC, estar na grande área das linguagens. Assim, políticas como texto e políticas como discurso constroem e reformulam as políticas educativas conforme interesses sociais.

Perceptível no cenário vigente que as políticas educativas divulgam necessidades de reformas do setor público e melhoramento escolar, apresentando críticas ao modelo público educacional, com justificativas diversas, para estabelecer um "conjunto de variadas articulações e apoios concretos, uma poderosa e extensa formação discursiva que exerce diferentes influências sobre os processos de reforma pública"(Ball, 2014, p. 3), no qual inúmeras empresas "vendem políticas, vendem reformas e vendem estratégias de melhoramento escolar em forma de enlatados, como ideias pré-fabricadas" (Ball, 2014, p. 11). Assim como em diversos países, no Brasil também já existem alguns Programas de governo baseados em alianças público privadas e iniciativas de financiamento privado. Exemplo disso é o "Future-se", programa do governo no âmbito nacional, que dá possibilidade de financiamento privado para pesquisas científicas das universidades públicas. No caso deste programa, percebe-se claramente a articulação não apenas de alianças entre setores do mercado, mas também, uma orientação para uma linguagem comum, sobre discursividades econômicas, na direção de transformações da forma e função das práticas educativas. Assim, processos como esse aludem a mudanças, maquiadas de progressistas, sem que se questione que "quando se defende a mudança na educação mobilizando o conhecimento político, está se colocando certas formas de conhecimento sobre políticas para serem usadas por meio de relacionamentos, atividades e discursos" (Ball, 2017, p. 35).

Formados por sujeitos, corporações e outras instituições, promove-se informações para a realização de investimentos de ordem privada na educação, na qual se prioriza a promoção de empresas e projetos educativos centrados na tecnologia (Ball, 2014). São inúmeros os programas tanto de ordem estadual, nacional e mundial. Um exemplo é o "Google for Education", programa da secretaria do estado de Santa Catarina em parceria com a Qi Network, que promove práticas pedagógicas baseadas no ensino híbrido, ou seja, forma de ensino por meio de ferramentas tecnológicas. Outro exemplo é o programa "Sala Web", no qual o estado tem parceria com os grupos Instituto Nature, Fundação telefônica e Inspirare. A plataforma Sala Web atualmente oferece mais de 3 mil conteúdos digitais, com inúmeros recursos, como vídeos, games etc.

O problema não está nos programas efetivamente, mas sim em o setor privado ser determinante na formulação e implementação de políticas públicas direcionadas a interesses próprios, principalmente de fim lucrativo, que Souza (2006) chama de neo-institucionalismo, o que pode causar, como já vem causando, um modelo contemporâneo que advoga que soluções procuram por problemas, para possibilitar o movimento do mercado. Para Ball (2017), desenvolvese uma base lógica aos processos de reforma da educação com argumentos, asserções e suposições, em relação ao Estado e sua alternativa, divulgando fracassos do Estado, crise na Educação com afirmação de que as escolas do governo são ineficazes e injustas. Incorporada e representada em diversos argumentos, tem-se uma versão da racionalidade neoliberal, que se configura como reformulação ou supressão das fronteiras do Estado, da economia e da sociedade civil. A problematização que se apresenta é de como o neoliberalismo vem se consolidando, "como parte de um movimento lento e constante do governo para a governança" (Ball, 2017, p. 39), onde a racionalidade neoliberal e sua mobilização e defesa são realizadas e demonstradas em práticas sócio materiais.

Larrosa (2002) e Arendt (2016), quando fazem críticas ao modelo de privatização educacional, na qual em suas escritas posicionam-se em defesa do coletivo, do público como sistema de educação, compreendem, assim como Ball $(2014$, p.3) que "novos tipos de negócios 
educativos, globais são formas de comércio e economia educativa, que transcendem a divisão educação pública/educação privada e transformam todos os serviços da educação em mercadoria".

\section{CONSIDERAÇÕES FINAIS}

Problematizar as relações envolvidas na produção da escola e na constituição de sujeitos escolares hodiernamente é uma tarefa a ser posta na agenda de discussões daqueles que se interessam pela compreensão dos fenômenos contemporâneos que produzem esses espaços e sujeitos. A escola, instituição notadamente moderna, organizada tal como conhecemos na emergência da sociedade disciplinar, conforme estudada por Foucault, e que possui características de forma e função ainda relativas a esse período, ao ser atravessada por novos contextos, interesses, tipos de comunicação, deslocamentos culturais que implicam em e são atravessados por novos tipos de subjetividades e regulações de população e mercados, deve, ainda, se manter tal como fora inicialmente proposta e gestada ou deveria abarcar as transformações atuais sob novas formas de vida e sociedade? Em suma: os atravessamentos da modernidade e da pós-modernidade, sobretudo com as articulações neoliberais em linguagens mercadológicas, ao disputarem espaços e sujeitos escolares alterando significativamente as formas e funções da escola, devem ser encarados através de quais perspectivas educacionais?

Nossa tese é de que a função da escola está em desenvolver dispositivos a partir de discursos que considerem gerações com capacidades de reinventar e transformar o seu mundo com responsabilidade sobre o coletivo e sobre o público, considerando uma formação crítica com vínculo ao social. Acreditamos que repensar o espaço escolar com características da modernidade em um cenário pós-moderno é potencializar funções imprescindíveis para continuação da nossa própria existência como sujeitos escolares como coletivo e público.

Partimos do pressuposto de que questionar os discursos potencializados da pósmodernidade na educação, que estão enraizados para o desenvolvimento da tecnociência, do progresso econômico e do ultra mercado, no qual interesses e reponsabilidades do Estado se deslocam e se mesclam a partir de ações sociais privadas no espaço escolar com interesses de mercado, passa a ser uma tarefa indispensável. Poder-se-ia pensar e sugerir, de modo a acrescer as problematizações realizadas e como direção de futuros estudos, uma discussão na direção de questões de políticas públicas educacionais, que cada vez mais promovem a expansão do comércio, mercado e privatização em educação, em escala global, na qual se tem promoção de empresas e projetos educativos centrados na tecnologia para fins lucrativos, que acabam por constituir formatos educativos em diversos campos como formação continuada de professores, programas, projetos e serviços, constituindo um novo cenário e modelo de escola e escolares.

Authors' Contributions: George Saliba Manske: concepção, desenho, escrita e aprovação final do manuscrito. Liliane Geisler: concepção, desenho, escrita e aprovação final do manuscrito. "Todos autores leram e aprovaram a versão final do manuscrito".

Ethics Approval: Não se aplica.

Acknowledgments: Não se aplica.

\section{REFERENCES}

Arendt, H. (2016). A condição humana. São Paulo: Editora Forense-Universitária.

Ball, S.J. (2006). What is Policy? Texts, trajectories and toolboxes. Discourse: Studies in the Cultural Politics of Education, 13(2), 10-17. https://doi/abs/10.1080/0159630930130203 
Ball, S. J. (2014). Globalización, mercantilización y privatización: tendencias internacionales en Educación y Política Educativa. Education Policy Analysis Archives, 22(41), 1-18. https://doi/abs/10.14507/epaa.v22n41.2014

Ball S. J. (2017) Laboring to Relate: Neoliberalism, Embodied Policy, and Network Dynamics. Peabody Journal of Education, 92(1), 29-41. https://doi/full/10.1080/0161956X.2016.1264802

Callegaro, R. (2012). Notas Sobre a Crise Na Educação No Pensamento De Hannah Arendt. Revista Educação E Políticas Em Debate, 1(1), 256-268.

Corazza, S. M. (2007). Composições. Belo Horizonte: Autêntica.

Costa, M. V., Silveira, R. H., \& Sommer, L. H. (2003). Estudos culturais, educação e pedagogia. Revista Brasileira de Educação, 23, 36-61. https://doi.org/10.1590/S1413-24782003000200004.

Costa, M. V., \& Momo, M. (2009). Sobre a "conveniência" da escola. Revista Brasileira de Educação 14(42), $521-533$. https://doi.org/10.1590/S1413-24782009000300009.

Dussel, I. (2017) Sobre a Precariedade da escola. In: Larrosa, J. (Org). Elogio da escola. Tradução de Fernando Coelho. Belo Horizonte: Autêntica Editora.

Hall, S. (2019). A identidade cultural na pós-modernidade. Tradução de Tomaz Tadeu da Silva e Guacira Lopes Louro. Rio de Janeiro: DP\&A,

Foucault, M. (2020). História da Sexualidade. Vol. II. O uso dos prazeres. Rio de Janeiro: Paz \& terra.

Foucault, M. (2014). A ordem do discurso: aula inaugural no Collége de France, pronunciada em 2 de dezembro de 1970. São Paulo: edições Loyola.

Larrosa, J. (2017). Pedagogia Profana: danças, piruetas e mascaradas. Belo Horizonte: Autêntica Editora.

Larrosa, J. (2002). Notas sobre a experiência e o saber de experiência. Revista Brasileira de Educação, 19, 20-28. https://doi.org/10.1590/S1413-24782002000100003.

Mattelart, A., \& Neveu, É. (2004). Introdução aos Estudos Culturais. Tradução de Marcos Marcionilo. São Paulo: Parábola Editorial.

Mendes, C. L., Cardoso, F. A., \& Matos, D. A. S. (2019). Currículo e relações de poder: análise de uma reforma curricular para cursos de pedagogia em tempos de conservadorismos. Revista Tempos E Espaços Em Educação, 12(30), 117-138. https://doi.org/10.20952/revtee.v12i30.9376

Moreira, A. F. B. (2012). Apresentação. Moreira, A. F. B.(org). Currículo: questões atuais. Campinas, SP: Papirus.

Moreira, A. F., \& Silva Júnior, P. M. da. (2016). Currículo, Transgressão e Diálogo: quando Outras Possibilidades se Tornam Necessárias. Revista Tempos e Espaços em Educação, 9(18), 45-54.

https://doi.org/10.20952/revtee.v9i18.4962

Nunes, C. P., Raic, D. F. F., \& Souza E. M. F. (2021). Education in the pandemic: questions about teaching work, curriculum and remote teaching. Revista Tempos e Espaços em Educação, 14(33), e16047.

https://doi.org/10.20952/revtee.v14i33.16047

Rose, N. (2001). Como se deve fazer a história do eu? Revista Educação \& Realidade, 26(1), 1-25.

Silva, T. T. (2007). Documentos de identidade: uma introdução às teorias do currículo. Belo Horizonte: Autêntica.

Souza, C. (2006). Políticas públicas: uma revisão da literatura. Sociologias, 16, 20-45. https://doi.org/10.1590/S1517$\underline{45222006000200003}$

YUDICE, G. (2004). A conveniência da cultura: usos da cultural na era global. Tradução de Marie-Anne Kremer. Belo Horizonte: Editora UFMG. 
Received: 31 June 2021 | Accepted: 22 September 2021 | Published: 11 October 2021

(c) (i)

This is an Open Access article distributed under the terms of the Creative Commons Attribution License, which permits unrestricted use, distribution, and reproduction in any medium, provided the original work is properly cited. 